\title{
Getting stable: an evaluation of the incentives for permanent contracts in Italy
}

\author{
Emanuele Ciani ${ }^{1,2^{*}}$ and Guido de Blasio ${ }^{3}$
}

\author{
* Correspondence: \\ emanuele.ciani@bancaditalia.it \\ ${ }^{1}$ Bank of Italy, Regional Economic \\ Research Division - Florence Branch, \\ via dell'Oriuolo 37/39, 50122 \\ Florence, Italy \\ ${ }^{2}$ Centre for the Analysis of Public \\ Policies, University of Modena and \\ Reggio Emilia, viale Berengario 51, \\ 41121 Modena, Italy \\ Full list of author information is \\ available at the end of the article
}

\begin{abstract}
There is little evidence as to the effectiveness of incentives for the conversion of fixed-term contracts into permanent jobs. We aim at filling this gap by studying a recent Italian program which provides benefits for employers who convert contracts for workers in specific demographic groups (females, younger men). Due to funding constraints, the incentives were available only for a few days, allowing us to employ a difference-in-differences strategy between similar short periods. Using administrative microdata for the Veneto region, we show that the subsidy increased conversions by $83 \%$ on average, with no substitution effects over time or across groups of workers.
\end{abstract}

JEL codes: J21, J41, J48

Keywords: Fixed-term contracts; Permanent employment; Diff-in-diffs

\section{Introduction}

During the last two decades, several European countries have shown a steep rise in the use of flexible contracts. This has increased attention towards policies aimed at promoting permanent employment, in particular during the ongoing economic crises. Several possible alternatives have been proposed and implemented in different countries, but the debate about their relative merits and problems is still open.

One solution would be to reduce the employment protection legislation of open-ended contracts, which should increase the overall job-turnover (Bertola 1990; Boeri and Jimeno 2005; Kugler and Pica 2008) and reduce the use of flexible contracts (Schivardi and Torrini, 2008; Grassi, 2009). This solution is nevertheless likely to be politically unfeasible. Another option would be to decrease the cost of permanent contracts. For instance, Hernanz et al. (2003) evaluate a Spanish reform in 1997 that broadly fit into this category. Although they found a positive effect on flows to permanent jobs, Mendéz (2013) criticizes their results and suggests that there was no effect on conversion rates. ${ }^{1}$ An alternative could also be to introduce a cost for terminating fixed-term contracts instead of converting them into permanent ones, as happened with a French reform in 2002. Maurin and Michaud (2004) provide evidence of an increase in the proportion of temporary contracts converted into permanent ones, but they also find that the higher costs induced a decrease in the number of new fixed-term hires. A fourth possibility would be to subsidize any hire with a permanent contract, as done, for instance, by an Italian program introduced in 2001 and evaluated by Cipollone and Guelfi $(2003,2006)$. The main problem is that employers are unlikely to directly sign 
permanent contracts without strong signals of high productivity from the workers. Hence a substantial part of the incentive is likely to go to hires that would have taken place even in the absence of a subsidy. Indeed, Cipollone and Guelfi $(2003,2006)$ found no evidence of aggregate effects, but their results suggest positive effects for previously employed individuals and for those with higher education.

Less is known about incentives targeted only to the conversion of fixed term contracts. ${ }^{2}$ This kind of scheme allows employers to freely hire temporary workers, possibly generating the efficiency gains related to greater flexibility, but at the same time reducing the risk that individuals incur in a series of fixed-term contracts. Given the information asymmetry between workers and potential employers, an incentive for a contract conversion might be more effective than one for any direct hires because it exploits the preference of employers to sign permanent contracts with workers that have already been screened. Indeed, the empirical literature on temporary contracts generally agrees that they represent a stepping stone to permanent employment, although the size of the effect may depend on the kind of contract and characteristics of the worker (Booth et al., 2002; Ichino et al. 2005; Picchio 2008; Barbieri and Sestito 2008; Berton et al. 2011; Bruno et al. 2012). Nevertheless, the ability of a program of this type to reach the stated target should not be taken for granted. For instance, Battiloro and Costabella (2011) evaluate a subsidy of around 4,500 euros for conversions, which was introduced in 2007 in the Province of Turin in Italy. By comparing the time series in Turin with those from other unaffected provinces, they find no evidence of an increase in the number of conversions.

In this paper we contribute to the literature by analyzing results relative to an Italian scheme, based on a December 5, 2012 decree, that subsidized conversions from fixedterm to open-end contracts. The policy did not apply to all groups of workers as it excluded men over 30. Furthermore, the funds were limited; as a matter of fact, they were exhausted in a couple of weeks. We elaborate on these features of the scheme and evaluate its effects through a diff-in-diffs strategy, which compares eligible workers with their non-eligible counterparts (older males) over very short periods of time. This strategy allows us to estimate the intention to treat effect (ITT) of the policy, which captures how the change in incentives altered the rate of conversion for eligible contracts during the period in which the subsidy was available.

Using aggregate time series from the Veneto region, Anastasia et al. (2013) showed that for the eligible groups the total number of conversions approximately doubled over the period of validity of the policy with respect to the previous year, and that there was a significant difference between the totals for men aged 29 and men aged 30. Differently from them, we directly use the microdata built from the administrative archives of the same region, a dataset that allows us to track individual fixed-term contracts over time. We focus on how their probability of conversion changed over different periods within 2012. In particular, we distinguish between periods with different exposure to the effects of the scheme (pre-announcement, announcement, treatment, end of funds). Apart from allowing us to focus on conversion rates rather than the time series of conversions, the use of microdata enables us to provide a deeper investigation of substitution effects and heterogeneity. We conduct an extensive series of robustness checks, and we also analyze whether transformation rates of men aged 30 or more decreased in firms where there were eligible colleagues. Furthermore, we study the effect 
on the individuals' probability of being employed with a permanent contract some months after the end of the scheme. Finally, we also discuss the heterogeneity of the effects by educational status and by number of fixed-term employees within the firm.

Our estimates suggest that the policy increased the probability of transformation by $83 \%$ with respect to the counterfactual rate of conversion, with larger effects for men under 30 and women over 30 and a smaller impact on younger women. There is no evidence that entrepreneurs postponed conversions during the short period between the announcement and the full implementation of the program or that they reduced the conversion rate after the funds were terminated; we also fail to find evidence that the impact is due to substitution between eligible and non-eligible workers. These results are robust to several checks, including a falsification exercise aimed at detecting infra-annual confounding trends. We finally show that the effect seems to have lasted for 7.5 months after the end of the policy, which is the time extension of the last available data at the moment of writing.

The paper is structured as follows. Section 2 outlines the policy. Section 3 presents the data, while Section 4 describes the identification strategy. Section 5 discusses the results. Section 6 compares the scheme with the previous policy introduced in Italy in 2001 to tentatively draw some conclusions for program design. Section 7 concludes.

\section{The program}

The 5 October 2012 Decree introduced financial incentives for employers who:

- converted ongoing fixed-term contracts for eligible workers into permanent ones; the incentive in this case was equal to 12,000 euros per conversion;

- stabilized workers with ongoing non-standard contracts (parasubordinati) or who had concluded a fixed-term or non-standard temporary contract in the previous 6 months and had been unemployed thereafter; similarly, this incentive amounted to 12,000 euros per stabilization;

- hired workers with a fixed-time contract, but only if this hire increased the total workforce of the firm. In this case, the benefit was between 3,000 and 6,000 euros depending on the length of the contract.

The scheme required that the job last for at least 6 months after the conversion/hire. ${ }^{3}$ To comply with this requirement, the actual incentives were distributed only after this period of time. Eligible workers were men under 30 and women of any age. In the case of permanent contracts on a part-time basis, the amount of the subsidy was proportionally reduced. Moreover, each employer could request at most 10 incentives.

The Decree made use of a dedicated national fund for the purpose of increasing employment of young people and women. The fund was set up by Law 201/2011 (December 2011), but details on how the money was to be used were not fully defined until 5 October 2012 when the Decree introducing the program was approved by the Ministry of Labor and Social Policies jointly with the Ministry of Economics and Finance. We therefore take the latter as the date of announcement of the program. Figure 1 depicts the timeline of the policy.

The incentive applied only to conversions/stabilizations/hires made after the official date of publication of the Decree: the $17^{\text {th }}$ of October. The program was supposed to 


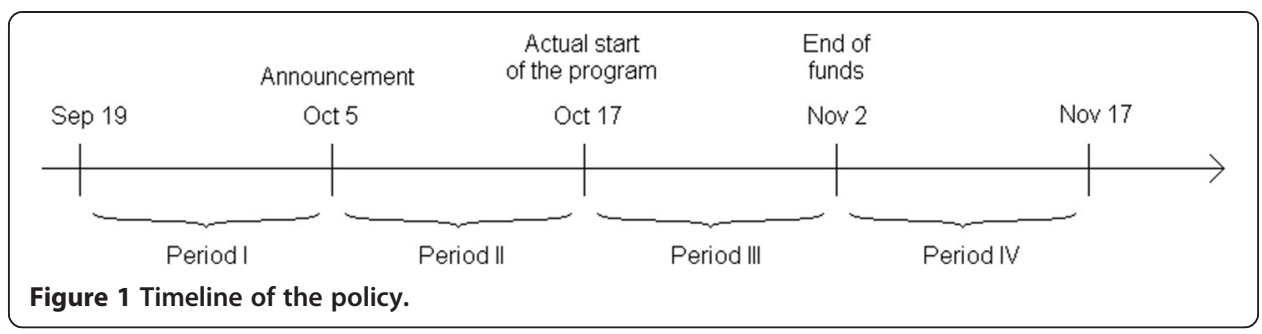

be in place up to the $31^{\text {st }}$ of March 2013. At the time of the formal application, the firms should have already signed (and communicated to the competent administration) the new contract with the eligible worker. Importantly, they could not make the contract conditional on the actual receipt of the incentive. Given that the funds were limited, employers could check online before making an application to see whether the number of requests made until then had already used up the total budget. However, if the funds terminated on the day of application, requests would be funded on a first-come-first-served basis, and those who turned out to be excluded could not cancel the conversion. On the $2^{\text {nd }}$ of November, the National Institute for Social Security (INPS) announced that the number of requests received until then would terminate the funds, and therefore the agency discouraged new applications. Some requests arrived after the $2^{\text {nd }}$ of November. This happened because it was not clear if all the applications already presented were actually eligible. Therefore, some employers might have applied, notwithstanding the INPS warning, hoping that they could still receive funding.

The only publicly available data on the program came from the Ministry of Labor website: at the national level, between 17/10/2012 and 31/03/2013, 44,054 requests were made, of which only 24,581 were accepted (Ministero del Lavoro e delle Politiche Sociali 2013). As to the acceptances, the firms were notified of acceptance only in June 2013 so as to comply with the requirement that the job had lasted at least 6 months. Given that the rules of the game were relatively simple, selection was mostly based on the order of presentation rather than on eligibility.

From the information released by the Ministry of Labor, we know that around $90 \%$ of all incentives were distributed for conversions or stabilizations of temporary contracts. Considering that the incentive for direct hires with fixed-term contracts was less generous (and required an increase in the overall workforce), it is not surprising that few requests were made for that option. Compared to fixed-term workers, the number of parasubordinati is much smaller; moreover, this group is highly heterogeneous as regards the features of the firm-employee relationship. For these reasons, in this paper we focus only on the conversions of ongoing fixed-term contracts, which could be subsidized if made between the $17^{\text {th }}$ of November until the end of funds $\left(2^{\text {nd }}\right.$ of November). We do not consider the case of those who had concluded a temporary contract within 6 months and had been unemployed thereafter. The main issue is that these individuals may also migrate to/from other regions, and therefore we cannot always track whether they become stabilized or not. Nevertheless, in the robustness section, we show that there is no evidence of change in the number of direct hires during the validity of the incentives. 


\section{Data}

Since March 2008 employers who hire new workers or modify pre-existing contracts are obliged to communicate such information to a regional agency through an online system called sistema di comunicazione obbligatoria (Anastasia et al. 2009, 2010). This administrative archive does not provide a complete stock of workers. Permanent and temporary contracts signed before March 2008 and that did not experience any modification (for instance a switch from full to part time or an extension in the case of temporary contracts) are not entered in the sistema di comunicazione obbligatoria dataset. However, this is not a problem if we want to focus on the stock of ongoing fixed-term contracts in the most recent years. The reason is that standard fixed-term contracts can be signed only for up to 36 months, and therefore their entire stock should be observable in the files starting from March 2011. ${ }^{4}$

The quality of these data depends not only on the accuracy of the employers but also on the skills of the regional agencies in charge of maintaining and validating the archives. In Italy, the region with the longest tradition in analyzing these data is Veneto (Maurizio 2006), where the local agency (Veneto Lavoro) started developing a dedicated software in 1996. Moreover, using the flow of communications, the agency organizes a full set of longitudinal microdata that track single individuals through time. Veneto Lavoro makes available to researchers the entire universe of microdata, while at the national level, these data are available only for a subset of workers (individuals born on 48 different dates) and, crucially, without any information about contract conversions. The Veneto region is one of the most important economic areas of the country: according to the Labor Force Survey, in 2012 Veneto accounted for 9.5\% of total employees in Italy and for $8.3 \%$ of total employees on temporary contracts.

We focus on the (regional) universe of job relationships that started with a standard fixed-term contract (tempo determinato) at any time and that were still active as fixedterm contracts for at least one day during some specific periods of 2012 (defined in the next section). These relationships might either keep their short-term nature or be converted into permanent positions. We analyze the extent to which there has been a change in the event "fixed contract converted into permanent" because of the program. We select only standard fixed-term contracts; that is, we exclude contracts that are activated to substitute a permanent worker on leave (per sostituzione), those signed with a temporary employment agency (interinale o a scopo di somministrazione), those allowing the employee to work at home (a domicilio), and those designed for particular sectors or for other particular reasons. ${ }^{5}$ We make very minor corrections on the raw data, dropping a few cases where we observed a change in the nature of the contract for no precise reason and correcting the date of conversion for some job-relationships where the conversion episode was repeated more than once. We also exclude very few cases (around $0.6 \%$ of those job-relationships that were subject to conversions) where the standard fixed-term contract was converted into a non-standard permanent contract because these may signal measurement error.

Using the longitudinal information on each job relationship $i=1, \ldots, N$, we build a panel over four different periods $t=1, \ldots, 4$ in 2012. The length of each period is between 12 and 16 days (the next section explains the details on these units of time). For each period, we keep only job-relationships that are active as fixed-term contracts; that is, fixed term contracts with at least one day of duration during the period. The panel 
is unbalanced for two reasons: a) new fixed-term contracts can be signed during the year; therefore, new job relationships can enter the panel in any period; b) fixed-term contracts terminate (either for the natural end of the contract or for other reasons) or are converted into permanent ones; these contracts exit the panel in the period after that in which the event takes place.

Our main outcome is a binary variable:

$$
y_{i t}=\mathbf{1}[\text { job - relationship } i \text { is converted from temporary to permanent in period } t]
$$

so that our results have to be interpreted as the impact of the scheme on the probability that a temporary contract active during a single period $t$ is converted into permanent during the period. The zero outcome includes different kinds of situations: contracts that continue as temporary in the same firms, contracts of workers who quit and then become unemployed, and contracts of workers who quit and then become employed. The interpretation of the main results is therefore how the policy affects the probability of experiencing a conversion versus any other outcome. The main concern for the evaluation of the policy is that the zeros may include individuals who leave a fixed-term contract and sign a permanent contract with another employer. In Section 5.4 we also present results on the probability of being in permanent employment (with any employer) some months after the end of the funds. Given that periods are of different length, one may find it difficult to interpret the results. To address this concern, in Section 5.1 we also calculate the effect as a proportion of the counterfactual and as total number of conversions. Furthermore, in Section 5.2 we discuss a model where the unit of measurement is the daily probability of conversion.

For each job-relationship we observe some time invariant characteristics: educational level of the worker, gender, sector of activity, and citizenship. ${ }^{6}$ We also know two important time variant observables: the worker's age at the start of each period and the job-relationship elapsed duration at the end of the period. ${ }^{7}$ Finally, we can identify the employer: this allows us to cluster the standard errors at the firm level and observe how many fixed-term contracts refer to the same firm at a particular moment in time.

From the panel, we drop those observations where age or gender are missing (21 in total), and we select only individuals aged between 16 and 65, mainly in order to avoid extreme cases that are likely to signal measurement error. We end up with 593,028 observations, approximately 148,000 job relationships per period.

\section{Identification strategy}

We use a diff-in-diffs strategy over different periods within 2012 and different groups in terms of program eligibility, defined on the basis of demographic characteristics. We focus on the impact the policy has on the eligible groups' conversion rates so that our estimates can be interpreted as the Intention To Treat (ITT). This effect is of interest for a policy maker who wants to understand whether the change in incentives designed by the policy had any impact on the likelihood that eligible contracts experienced a conversion. Although our data do not contain information as to who actually received the incentive, it should be noticed that we only need eligibility to estimate the ITT. 
Neither information about the total number of subsidies actually received nor an indicator for the actual treatment status are required. Nevertheless, in Section 5 we also calculate the actual cost for each increased unit of conversion in a scenario in which all transformations for the eligible groups are incentivized. ${ }^{8}$

Following the standard model (Angrist and Pischke 2009), we assume that the expected potential outcome when not treated (indexed by 0 ) depends additively on the group $g$ and on the period $t$ :

$$
E\left[y_{0 i g t} \mid g, t\right]=\mu_{g}+\lambda_{t}
$$

which implies two basic assumptions (Blundell and MaCurdy 1999):

A1.The time trend is parallel across groups.

A2. The group effect does not change over time; that is, the group composition is (on average) constant.

Secondly, we assume that the effect of the policy is additive so that the potential outcome when treated (indexed by 1 ) is simply

$$
E\left[y_{1 i g t} \mid g, t\right]=E\left[y_{0 i g t} \mid g, t\right]+\delta=\mu_{g}+\lambda_{t}+\delta
$$

Exploiting the timeline of the policy (see Figure 1), we define 4 periods of interest:

- Period I: [19/09 - 4/10]; that is, 16 days before the announcement.

- Period II: [5/10 - 16/10]; that is, the 12 days between announcement and the actual start of the program.

- Period III: [17/10 - 01/11]; that is, the 16 days when the incentives were fully available.

- Period IV: [02/11 - 17/11]; that is, the 16 days after INPS declared that funds were (presumably) already used up.

We assume that in Period I the policy will not have any effect: only on the $5^{\text {th }}$ of October was the scheme of incentives made public, receiving full attention from the media. Consequently, most of the activity will take place in Period III, given that employers will already have had enough time to acquire the information. However, the effect of the policy may not be limited to changes during that period if employers have substituted conversions over time in order to benefit from the incentives. ${ }^{9}$ To start with, if they were already fully informed during Period II, they may have postponed some conversions in order to wait for the scheme to be in place. Moreover, the fact that funds were limited clearly might have given them a strong incentive to anticipate Period III conversions that would have taken place, without the scheme, much later in time. This is the reason why we also analyze the days after the shortage of funding (Period IV). In both cases (periods II and IV), we expect that if employers have substituted conversions over time in order to benefit from the incentives, the effect of the policy should compensate those observed in Period III. The lengths of Periods I and IV were chosen in order to match the period of full validity of the incentives. 
The groups entitled to the scheme are defined by the policy: men over 30 were not eligible, while younger men and women of any age were. We allocate individuals to each group according to their age at the beginning of the period. ${ }^{10}$

In order to identify the effect $\delta$, we exploit the structure of entitlement envisaged by the policy. Given that men over 30 were not eligible, we use these workers as a control group to estimate the trend over periods of time and then use it to clear the time effects for other groups as well, thanks to assumption A1. Once we are able to identify $\lambda_{t}$, we also need to clear out the group effect. In this case, we exploit the period before the announcement (Period I). If, as we argued, the policy could not have any effect at that time, then during that period we observe only $y_{0}$ for everyone; therefore, we can use it to identify the differences across groups. Finally, for the eligible workers in the post-announcement periods (II-III-IV), we observe only the outcome when treated $\left(y_{1}\right)$, and therefore we can remove from it the time and group components to get the policy effect $\delta$.

Our results are derived from a specification where the treatment effect $\delta$ varies by period of treatment (II-III-IV) and across eligible groups. This is equivalent to a series of $2 X 2$ diff-in-diffs estimates, where the control group is always men over 30 , and the pre-reform period is always Period I. For each single group (men under 30, women under 30 and women aged 30+), or for all the eligible groups altogether, the effects of interest can be identified from the coefficients on the interaction terms:

$$
\begin{aligned}
& y_{i t}=\beta_{0}+\beta_{E} \mathbf{1}[\text { Eligible }]_{i t}+\beta_{I I} \mathbf{1}[\text { Period II }]_{i t}+\beta_{I I I} \mathbf{1}[\text { Period III }]_{i t}+\beta_{I V} \mathbf{1}[\text { Period IV }]_{i t}+ \\
& +\delta_{I I} \mathbf{1}[\text { Eligible }]_{i t} \times \mathbf{1}[\text { PII }]_{i t}+\delta_{I I I} \mathbf{1}[\text { Eligible }]_{i t} \times \mathbf{1}[\text { PIII }]_{i t}+\delta_{I V} \mathbf{1}[\text { Eligible }]_{i t} \times \mathbf{1}[\text { PIV }]_{i t}+\varepsilon_{i t}
\end{aligned}
$$

For $\delta$ to identify a causal effect, we need to assume that the policy was an exogenous shock so that the treated groups were not endogenously chosen among those that would have experienced an increase in conversion rates anyway. This potential threat seems to be hardly realistic: eligibility was targeted on workers who were more likely to be hit by the on-going economic crisis. Furthermore, our estimates are based on relatively short periods of time, ordered in succession. Hence, it is difficult to imagine that, in the absence of the policy, the conversion rate would change abruptly only during the 16 days in which incentives were fully available.

The presence of a control group and the comparison with non-treated periods should clear out unobserved heterogeneity in the estimation of the effect of the policy on the rate of conversion during Period III (the ITT discussed above), as long as we do not find evidence of other forms of substitution over time or across different kinds of workers. Clearly, this is not sufficient to draw conclusions about the longer term effects on other outcomes (for instance, labor productivity) of additional conversions induced by the policy. This would require new data and a different strategy comparing subsidized conversions with those that did not receive any incentive; therefore, we defer that matter to future research projects. One important critique is that, even in the short term, employers may have made conversions only in order to access the benefits and later dismiss the worker after the six months required by the decree. The stronger EPL associated with permanent contracts should reduce the likelihood of this strategic behavior, but it should be taken into account that the legislation is weak in smaller firms. 
To address this concern, in Section 5.4 we also study the effect of the policy on the probability of being permanently employed some months later, and we show that permanent employment lasted up to 7.5 months after the end of Period III (that is, until the most recent data available at the time of writing).

There are other threats to identification. First of all, there may be seasonal trends that diverge across groups. Since we estimate the effect of the scheme for very short periods of time during Fall 2012, group-specific seasonality might unduly confound identification. In the empirical section below, we check whether this is the case by running a falsification test using 2011 calendar periods analogous to the ones we focus on for the year 2012.

Secondly, the panel is unbalanced. This implies that group composition is not guaranteed to be stable over time. To lessen this concern, we run the same regressions but add a large set of covariates (educational level, sector of activity, citizenship, age at the beginning of the period, elapsed duration of the job-relationship at the end of the period), which should differentiate our overtime variations in group compositions.

Thirdly, we need to assume that in Period I, employers were not aware of the policy, or at least that the information available was not enough for them to already change their decisions in order to later benefit from the incentives. To test this assumption, we run a diff-in-diffs regression that compares the different groups between Period I in 2012 and the analogous period in 2011.

Last but not least, apart from substitution over time, which we directly addressed by looking at periods II and IV, there may be other reactions that counteracted the effectiveness of the scheme. The most likely is that the incentives could have induced employers to favor workers from eligible demographic groups and thus reduce conversions for the non-eligible (men over 30). We provide evidence regarding this potential channel of substitution by looking at the change in the conversion rate for non-eligible workers during the same periods in 2012 and the previous year. Furthermore, as a consequence of the policy, employers could have indirectly subsidized direct hires with permanent contracts by hiring workers with fixed-term contracts and converting them after a few days. Similarly, they could have favored conversions with respect to direct hires. We also show what happens during the periods of validity, and relatively to 2011, to the number of jobs starting with permanent contracts.

\section{Results}

\subsection{Main results}

Figure 2 shows the rate of conversion for each of the four periods across groups in 2012. Before the announcement (Period I), the rates of conversion are similar for all groups, with only a slightly smaller probability for older women. In Period III the probability that a fixed-term contract will become permanent substantially increases for all the eligible groups compared to the non-eligible one. The jump is larger for younger men. The figure also shows no sign of substitution effects over time: in Period II and Period IV the rates remain quite similar across the groups.

The diff-in-diffs regressions (Table 1) confirm the findings. ${ }^{11}$ Focusing on the entire group of eligible workers, Column (1), there is no evidence of an anticipation effect during the days between the announcement and the actual date of validity (Period II): although there is a decrease in the overall conversion rate, this does not diverge 


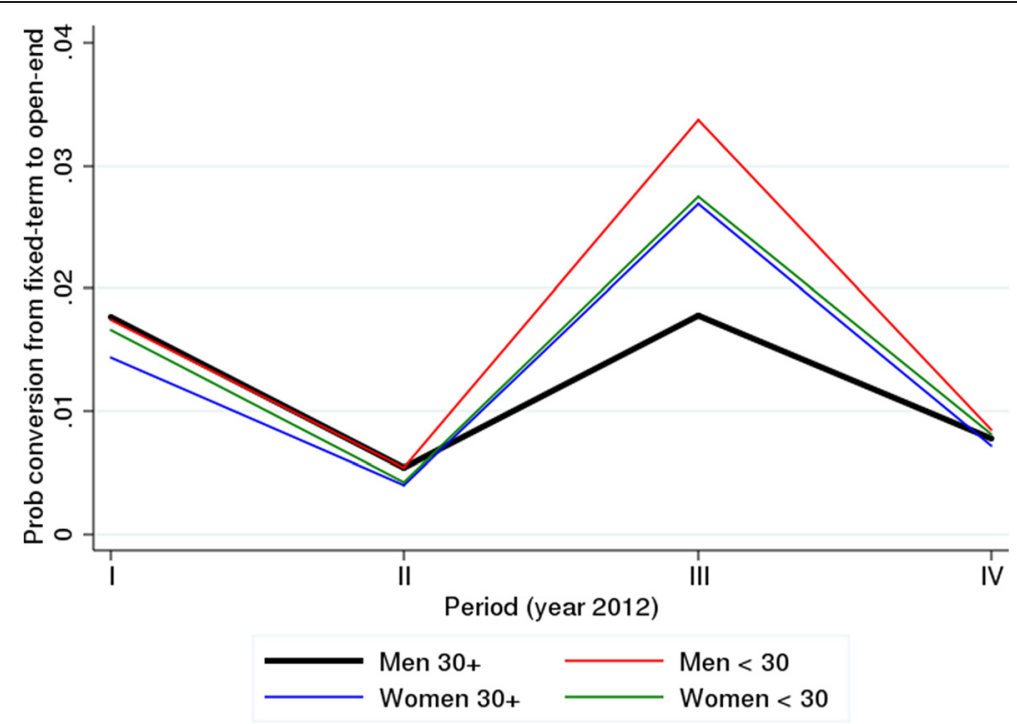

Figure 2 Conversion rate in 2012; Probability of conversion from fixed-term to permanent contracts during the period, by period and group, year 2012.

between eligible and control groups. Likely, employers became fully aware of the scheme when the program was about to start; therefore, substantial arbitrage across periods was precluded. Consequently, there is a significant increase in the conversion rate by 1.3 percentage points during the 16 days in which incentives were available and fully funded (Period III).

Table 1 Main results (probability of conversion from fixed-term to permanent contracts during each single period in 2012)

\begin{tabular}{|c|c|c|c|c|}
\hline Control group: Men $\geq 30$ & (1) & $(2)$ & (3) & (4) \\
\hline \multirow{2}{*}{$\begin{array}{l}\text { Dependent variable: } \\
\text { dummy for conversion }\end{array}$} & \multicolumn{4}{|c|}{ Eligible group: } \\
\hline & All eligibles & Men $<30$ & Women $<30$ & Women $\geq 30$ \\
\hline \multirow[t]{2}{*}{ Eligible } & $-0.0021^{* * *}$ & -0.0003 & -0.0011 & $-0.0034^{* * *}$ \\
\hline & $(0.0007)$ & $(0.0011)$ & $(0.0011)$ & $(0.0009)$ \\
\hline \multirow[t]{2}{*}{ Period II } & $-0.0123^{* * *}$ & $-0.0123^{* * *}$ & $-0.0123^{* * *}$ & $-0.0123^{* * *}$ \\
\hline & $(0.0007)$ & $(0.0007)$ & $(0.0007)$ & $(0.0007)$ \\
\hline \multirow[t]{2}{*}{ Period III } & 0.0001 & 0.0001 & 0.0001 & 0.0001 \\
\hline & $(0.0009)$ & $(0.0009)$ & $(0.0009)$ & $(0.0009)$ \\
\hline \multirow[t]{2}{*}{ Period IV } & $-0.0099 * * *$ & $-0.0099^{* * *}$ & $-0.0099 * * *$ & $-0.0099^{* * *}$ \\
\hline & $(0.0008)$ & $(0.0008)$ & $(0.0008)$ & $(0.0008)$ \\
\hline \multirow[t]{2}{*}{ Eligible $\times$ Period II } & 0.0011 & 0.0004 & 0.0000 & $0.0020^{* *}$ \\
\hline & $(0.0008)$ & $(0.0012)$ & $(0.0013)$ & $(0.0010)$ \\
\hline \multirow[t]{2}{*}{ Eligible $\times$ Period III } & $0.0130^{* * *}$ & $0.0162^{* * *}$ & $0.0107^{* * *}$ & $0.0124^{* * *}$ \\
\hline & $(0.0012)$ & $(0.0019)$ & $(0.0019)$ & $(0.0014)$ \\
\hline \multirow[t]{2}{*}{ Eligible $\times$ Period IV } & $0.0020^{* *}$ & 0.0010 & 0.0014 & $0.0027^{* * *}$ \\
\hline & $(0.0009)$ & $(0.0014)$ & $(0.0014)$ & $(0.0010)$ \\
\hline \multirow[t]{2}{*}{ Constant } & $0.0177^{* * *}$ & $0.0177^{* * *}$ & $0.0177^{* * *}$ & $0.0177^{* * *}$ \\
\hline & $(0.0007)$ & $(0.0007)$ & $(0.0007)$ & $(0.0007)$ \\
\hline Observations & 593,028 & 324,463 & 304,880 & 423,177 \\
\hline
\end{tabular}

Note: ${ }^{*} \mathrm{p}<.10{ }^{* *} \mathrm{p}<.05{ }^{* * *} \mathrm{p}<.01$. Standard errors clustered for employer in brackets. Estimates are obtained using Stata ${ }^{\mathrm{TM}} 13$. See Figure 1 for the definition of periods. 
Our results also document a positive effect of the scheme in Period IV, that is, after the day on which INPS announced that applications were already sufficient to exhaust funds. One possible explanation is that some employers might have realized that the funds were (probably) terminated only after having signed a permanent contract with a fixed-term worker; alternatively, they might have converted on purpose after the $2^{\text {nd }}$ November, in the expectation that some public money was left for them to receive (see Section 2).

Columns (2)-(4) document the results for each single group of eligible employees. For workers under 30, there is evidence of a positive effect of the policy in Period III. The impact is greater for men, less for women. As for the other two periods, there is no statistically significant change with respect to the control group. For older women we still find a positive effect of the policy in Period III. However, there is also evidence of a positive effect in Periods II and IV; the magnitude is around 0.2-0.3 percentage points. These findings might suggest a diverging trend for this specific group, which would infringe upon assumption A1 rather than being an actual policy effect. In particular, while the impact in Period IV can be rationalized on the basis of the scattered timing of the actual end of the scheme, the effect in Period II is puzzling. If nothing, we would have expected a decrease in the conversion rate for eligible workers in the time window between announcement and beginning of validity. To take a cautious stance, we might be overestimating the effect of the program for this specific group. The overestimation should not be a great concern if we interpolate the observed diverging trend, the bias would be around 0.2-0.3 percentage points, bringing the effect for women, aged at least 30 , closer to that for younger ones.

Table 2 provides some back-of-the-envelope calculations. Given that we do not know who actually received the incentives, we assume that all eligible conversions in Period III were subsidized. ${ }^{12}$ This gives an upward estimate for the actual cost because some conversions may have been excluded from the incentives as a consequence of the shortage of funding. However, this calculation is still of interest as it shows the effectiveness of the program in a normal situation where all eligible conversions receive a subsidy.

First, we compute the proportional increase in conversions due to the program as the ratio between the estimated effect in Period III and the counterfactual conversion rate predicted by the model. ${ }^{13}$ As a share of the counterfactual conversions predicted in

Table 2 Summary of the effects

\begin{tabular}{lllll}
\hline & All eligibles & Men < 30 & Women < 30 & Women $\geq \mathbf{3 0}$ \\
\hline $\begin{array}{l}\text { Counterfactual conversion rate from fixed-term to } \\
\text { permanent during period III }\end{array}$ & 0.0157 & 0.0175 & 0.0167 & 0.0145 \\
$\begin{array}{l}\text { Policy effect in period III } \\
\text { Counterfactual number of conversions during period III }\end{array}$ & 0.0130 & 0.0162 & 0.0107 & 0.0124 \\
Policy effect in number of conversions during period III & 1,156 & 402 & 307 & 684 \\
Policy effect/counterfactual rate & $83 \%$ & $92 \%$ & 197 & 589 \\
\% full time on total conversions in period III & $62 \%$ & $84 \%$ & $56 \%$ & $86 \%$ \\
Average incentive (euro) & 9,693 & 11,047 & 9,345 & $50 \%$ \\
Full cost per increased conversion (euro) & 21,392 & 23,008 & 23,889 & 19,472
\end{tabular}

Note: the number of conversions is calculated as the estimated probability times the number of fixed-term contracts active in Period III. The second column does not precisely sum up the following three because the estimate of the effect comes from the aggregate model (Table 1, col. (1)). The average cost of a conversion is calculated assuming that all part-time are at half time. 
Period III, the impact of the program amounts to $92 \%$ for young men, $86 \%$ for older women, and $64 \%$ for females under 30 . The average effect for all the eligible groups is calculated to be $83 \%$. This latter figure implies that in order to increase the number of conversions by one unit, the government has also financed 1.2 conversions that would have taken place even in the absence of the program. Given that our data refer to the universe of all fixed-term contracts (started with a standard type) for workers aged 1565 in Veneto, we can also compute the effect of the scheme in terms of number of contracts by multiplying the number of observations for the estimated probabilities. Among 2,551 conversions observed in Veneto in Period III, 1,156 of them are attributable to the program. Moreover, using the information on whether the converted contract is full or part time, we are also able to estimate the average incentive and the average cost per increased conversion. As reported in Table 2, on average, $62 \%$ of the job-relationships subject to conversion in Period III were full-time. Assuming that all the part-times were at half of the standard working time, the average incentive was 9,693 euros. ${ }^{14}$ This implies that the full cost of an actual unit increase in the number of conversions with respect to the counterfactual conversion is 21,392 euros, as it requires an expenditure of 11,700 euros for other transformations that would have taken place even in the absence of the policy.

One important critique to this calculation is that, due to the short duration of the policy, the effect observed during Period III comes mainly from the most informed firms and from those employers who are more reactive to these kinds of incentives. On the one hand, this would induce a bias in our estimates only if this additional effect is simply due to a strategic substitution of conversion over time or between eligible and non-eligible workers. In the next subsection, we propose a full set of robustness checks to argue that this was not the case, at least overall. On the other hand, this selfselection may imply that all of the potential demand for incentives related to actual additional conversions was already exhausted by the available funds. We cannot therefore say whether additional funding and a longer extension of the program would have increased the effect.

\subsection{Robustness checks}

Given that our periods are different, both in terms of months and calendar position within the month, the conversion rate across time might be affected by seasonal patterns. In our case, seasonality would bias the results only as long as there are groupspecific seasonal trends. To check whether this problem affects our estimates, we also replicate the same exercise of Table 1 over the analogous periods in year 2011 when the scheme was not in place (and no similar policy was implemented). ${ }^{15}$ That is, we run a falsification experiment. From Figure 3, which mirrors Figure 2 but refers to 2011, we notice no evidence of diverging trends. The comparison with the previous year also shows that the reduced overall conversion rate in Periods II and IV is not due to substitution over time, that is, to employers who postponed or anticipated to Period III conversions of contracts for any type of worker in order to benefit from the incentives. On the contrary, the reduction is due to the fact that the two periods do not include either the beginning or end of the month, when conversions usually take place, and to the shorter length of Period II. This seasonality, which does not differ across groups, was present in 2011 as well, with rates very similar to 2012. 


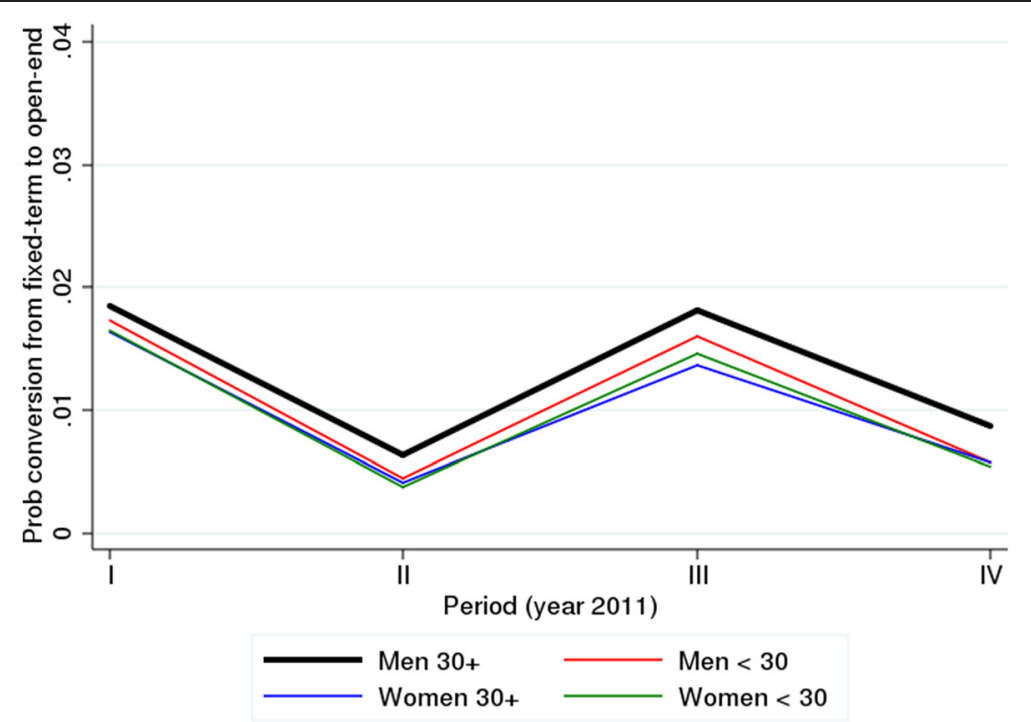

Figure 3 Conversion rate in 2011; Probability of conversion from fixed-term to permanent contracts during the period, by period and group, year 2011.

Table 3 reports the relevant regression estimates. In Column (1), we find evidence of a slight (boundary statistically significant at the 10\% level; p-value 0.095) drop in Period III for the groups of interest, which would either imply that our results underestimate the true effect (if the drop had been there even in the absence of the policy) or that differential (by groups and periods) shocks to conversion rates materialized. However, the

Table 3 Falsification (probability of conversion from fixed-term to permanent contracts during each single period in 2011)

\begin{tabular}{|c|c|c|c|c|}
\hline Control group: Men $\geq 30$ & (1) & $(2)$ & (3) & (4) \\
\hline Dependent variable: dummy for conversion & All eligibles & Men $<30$ & Women $<30$ & Women $\geq 30$ \\
\hline \multirow[t]{2}{*}{ Eligible } & $-0.0018^{* *}$ & -0.0012 & -0.0020 & $-0.0021^{* *}$ \\
\hline & $(0.0008)$ & $(0.0010)$ & $(0.0013)$ & $(0.0010)$ \\
\hline \multirow[t]{2}{*}{ Period II } & $-0.0121^{* * *}$ & $-0.0121^{* * *}$ & $-0.0121^{* * *}$ & $-0.0121^{* * *}$ \\
\hline & $(0.0008)$ & $(0.0008)$ & $(0.0008)$ & $(0.0008)$ \\
\hline \multirow[t]{2}{*}{ Period III } & -0.0003 & -0.0003 & -0.0003 & -0.0003 \\
\hline & $(0.0009)$ & $(0.0009)$ & $(0.0009)$ & $(0.0009)$ \\
\hline \multirow[t]{2}{*}{ Period IV } & $-0.0097^{* * *}$ & $-0.0097^{* * *}$ & $-0.0097^{* * *}$ & $-0.0097^{* * *}$ \\
\hline & $(0.0008)$ & $(0.0008)$ & $(0.0008)$ & $(0.0008)$ \\
\hline \multirow[t]{2}{*}{ Eligible $\times$ Period II } & -0.0004 & -0.0008 & -0.0006 & -0.0002 \\
\hline & $(0.0009)$ & $(0.0011)$ & $(0.0014)$ & $(0.0010)$ \\
\hline \multirow[t]{2}{*}{ Eligible $\times$ Period III } & $-0.0018^{*}$ & -0.0009 & -0.0016 & $-0.0024^{*}$ \\
\hline & $(0.0011)$ & $(0.0014)$ & $(0.0018)$ & $(0.0013)$ \\
\hline \multirow[t]{2}{*}{ Eligible $\times$ Period IV } & -0.0012 & -0.0017 & -0.0013 & -0.0008 \\
\hline & $(0.0009)$ & $(0.0012)$ & $(0.0014)$ & $(0.0011)$ \\
\hline \multirow[t]{2}{*}{ Constant } & $0.0184^{* * *}$ & $0.0184^{* * *}$ & $0.0184^{* * *}$ & $0.0184^{* * *}$ \\
\hline & $(0.0007)$ & $(0.0007)$ & $(0.0007)$ & $(0.0007)$ \\
\hline Observations & 614,895 & 340,214 & 313,218 & 438,457 \\
\hline
\end{tabular}

Note: ${ }^{*} p<.10 * * p<.05 * * * p<.01$. Standard errors clustered for employer in brackets. See Figure 1 for the definition of periods. 
estimate for Period III in the falsification exercise is quite small compared to the effect estimated for the same period in 2012, when the policy was effective. If we look at results for the different eligible groups (columns (2)-(4) in Table 3), the slight drop in Period III seems to be driven only by older women (again the coefficient is significant only at the $10 \%$ level). Notice also that the size of this drop, 0.2 percentage points, would broadly compensate the previously discussed positive bias for this specific demographic group. ${ }^{16}$

Given that the panel is unbalanced, the group composition is not guaranteed to be stable over time. ${ }^{17}$ In order to see whether large changes in the group composition are affecting the results, in Table 4, column (1), we also add to the basic regression (that of Table 1, Column 1) some relevant covariates: dummies for sector of activity (NACE Rev. 2 sections, composed of 21 categories), dummies for educational level, a dummy for Italian citizenship, age at the beginning of the period, and job-relationship elapsed duration at the end of the period. ${ }^{18}$ The results are basically unchanged. Therefore, time variation in group composition seems not to be driving our findings. Column (2) provides the results we obtain by adding the covariates to the falsification experiment. The bizarre effect found previously in Period III is no longer statistically significant.

Table 4 Robustness checks (probability of conversion from fixed-term to permanent contract during each single period)

\begin{tabular}{|c|c|c|c|c|c|}
\hline $\begin{array}{l}\text { Control group: } \\
\text { Men } \geq 30\end{array}$ & (1) & $(2)$ & (3) & (4) & (5) \\
\hline $\begin{array}{l}\text { Treatment } \\
\text { group: all } \\
\text { eligible } \\
\text { Dependent } \\
\text { variable: dummy } \\
\text { for conversion }\end{array}$ & $\begin{array}{l}\text { Main results } \\
\text { over } 2012 \text { with } \\
\text { covariates }\end{array}$ & $\begin{array}{l}\text { Falsification } \\
\text { over } 2011 \text { with } \\
\text { covariates }\end{array}$ & $\begin{array}{l}\text { Main results } \\
\text { over } 2012 \text { with } \\
\text { age }[26,34]\end{array}$ & $\begin{array}{l}\text { Falsification } \\
\text { over } 2011 \text { with } \\
\text { age }[26,34]\end{array}$ & $\begin{array}{l}\text { Main results } \\
\text { on closed sample } \\
\text { (only fixed-term } \\
\text { contracts active } \\
\text { in period I) }\end{array}$ \\
\hline \multirow[t]{2}{*}{ Eligible } & $-0.0017^{* *}$ & -0.0008 & -0.0004 & -0.0023 & $-0.0021^{* * *}$ \\
\hline & $(0.0008)$ & $(0.0008)$ & $(0.0015)$ & $(0.0016)$ & $(0.0007)$ \\
\hline \multirow[t]{2}{*}{ Period II } & $-0.0129^{* * *}$ & $-0.0126^{* * *}$ & $-0.0140^{* * *}$ & $-0.0156^{* * *}$ & $-0.0121^{* * *}$ \\
\hline & $(0.0007)$ & $(0.0008)$ & $(0.0015)$ & $(0.0015)$ & $(0.0008)$ \\
\hline \multirow[t]{2}{*}{ Period III } & -0.0009 & -0.0012 & -0.0008 & -0.0012 & $0.0022^{* *}$ \\
\hline & $(0.0009)$ & $(0.0009)$ & $(0.0019)$ & $(0.0019)$ & $(0.0010)$ \\
\hline \multirow[t]{2}{*}{ Period IV } & $-0.0117^{* * *}$ & $-0.0112^{* * *}$ & $-0.0105^{* * *}$ & $-0.0134^{* * *}$ & $-0.0085^{* * *}$ \\
\hline & $(0.0008)$ & $(0.0008)$ & $(0.0017)$ & $(0.0016)$ & $(0.0008)$ \\
\hline \multirow[t]{2}{*}{ Eligible $\times$ Period II } & $0.0014^{*}$ & -0.0003 & 0.0002 & 0.0023 & 0.0012 \\
\hline & $(0.0008)$ & $(0.0009)$ & $(0.0017)$ & $(0.0018)$ & $(0.0008)$ \\
\hline \multirow[t]{2}{*}{ Eligible × Period III } & $0.0134^{* * *}$ & -0.0017 & $0.0153^{* * *}$ & 0.0003 & $0.0147^{* * *}$ \\
\hline & $(0.0012)$ & $(0.0011)$ & $(0.0024)$ & $(0.0022)$ & $(0.0013)$ \\
\hline \multirow[t]{2}{*}{ Eligible × Period IV } & $0.0026^{* * *}$ & -0.0008 & 0.0000 & 0.0009 & 0.0014 \\
\hline & $(0.0009)$ & $(0.0009)$ & $(0.0019)$ & $(0.0019)$ & $(0.0010)$ \\
\hline \multirow[t]{2}{*}{ Constant } & $0.0063^{* * *}$ & $0.0069^{* * *}$ & $0.0193^{* * *}$ & $0.0210^{* * *}$ & $0.0177^{* * *}$ \\
\hline & $(0.0011)$ & $(0.0011)$ & $(0.0014)$ & $(0.0014)$ & $(0.0007)$ \\
\hline Observations & 593,028 & 614,891 & 145,803 & 156,147 & 539,923 \\
\hline
\end{tabular}

Note: ${ }^{*} \mathrm{p}<.10{ }^{* *} \mathrm{p}<.05{ }^{* * *} \mathrm{p}<.01$. Standard errors clustered for employer in brackets. See Figure 1 for the definition of periods. Covariates in columns (1)-(2) include dummies for sector of economic activity (NACE Rev. 2 sections), dummies for educational level, a dummy for Italian citizenship, age at the beginning of the period, and elapsed duration of the job-relationship at the end of the period. Missing values for the sector of activity have been excluded (only 4 observations in 2011), while missing values for educational level have been kept but adding a specific dummy. Coefficients are available on request. 
One may also criticize the use of treatment and control groups with large differences in terms of average age. Column (3) shows that our results are robust to selecting only individuals around the age cut-off. For this experiment, we make use of the interval $[26,34)$. The estimated effect is larger in percentage points but quite close to the baseline results if measured as a proportion of the counterfactual conversion rate. Similar results are obtained by choosing only individuals aged between 29 and 30. Furthermore, we also checked whether the effect is there by focusing on men only and running the dif-in-dif regressions by progressively shrinking the age range around 30 in order to approach a regression discontinuity design. Results are in line with those presented in the text. See Additional file 1 for the estimate table.

The effect in the age-restricted sample may actually highlight a possible substitution issue. While workers of different age groups may be imperfect substitutes, the degree of substitutability may be quite strong between men aged $[26,30)$ and those aged $[30,34)$. We replicated the main regression for men from Table 1 by dropping those aged $[30,35)$. Results are basically unchanged (see Additional file 1). ${ }^{19}$

We assumed that firms did not anticipate the policy during Period I so that we could use it to consistently estimate the group effects. This is not necessarily true if firms were already aware of how the government would use the fund established by Law 201/2011, which passed in December 2011. To test whether this was the case, we estimate a diff-in-diffs regression with the same control/treatment groups but consider only two periods: Period I in 2012 and Period I in 2011. If eligible groups were affected by the scheme already in Period I of 2012, then we should find evidence of an effect when comparing it with the analogous period in 2011 (using men over 30 as a control). We estimate the following specification:

$$
\mathrm{y}_{\mathrm{it}}=\gamma_{0}+\gamma_{\mathrm{E}} \mathbf{1}\left[\text { Eligible }_{\mathrm{it}}+\gamma_{2012} \mathbf{1}[\text { year 2012 }]_{\mathrm{it}}+\delta_{\mathrm{I}} \mathbf{1}\left[\text { Eligible }_{\mathrm{it}} \times \mathbf{1}[\text { year 2012 }]_{\mathrm{it}}+\eta_{\mathrm{it}}\right.\right.
$$

We find that the coefficient on the interaction is not statistically (or economically) significant, given that it is 0.03 percentage points. A similar result is obtained by disaggregating different groups, as in Table 1, Columns (2)-(4). Therefore, there seems to be no evidence that firms anticipated the implementation of the program before its announcement. Similar diff-in-diffs results between Period III in 2012 and the analogous period in 2011 confirm the presence of an effect, although estimates are somewhat larger (around 1.8 percentage points for men under 30 and 1.3 for both groups of women).

Besides anticipation and/or delay effects, which refer to the eligible groups, employers could have also substituted conversions for the control group in favor of those for eligible workers. If this happened, we would expect to find the trend over the four periods for the control group to show a dip in Period III. Given that a similar dip could have been present also in 2011, we tested whether the trend over periods I to IV was different in 2012 with respect to 2011. Results are reported in Table 5, column (1). A test for interactions between the dummy for 2012 and the dummies for periods II-III-IV being jointly equal to zero failed to reject the null, with a p-value of 0.9381 . Therefore, the evidence is not contrary to the assumption that the control group has not been affected (on average) by the policy. Clearly, substitution is more likely to occur in those firms where men over 30 have other colleagues on fixed-term contracts who are eligible for the 
Table 5 Test for a reduction in the control group: change in conversion rate trends across periods, 2012 vs 2011

\begin{tabular}{|c|c|c|c|c|}
\hline & (1) & (2) & (3) & (4) \\
\hline $\begin{array}{l}\text { Dep. var.: dummy } \\
\text { for conversion }\end{array}$ & Men $\geq 30$ & $\begin{array}{l}\text { Men } \geq 30 \text { with no } \\
\text { eligible colleagues }\end{array}$ & $\begin{array}{l}\text { Men } \geq 30 \text { with } \\
\text { eligible colleagues }\end{array}$ & $\begin{array}{l}\text { Men } \geq 30 \text { with one } \\
\text { eligible colleague }\end{array}$ \\
\hline \multirow[t]{2}{*}{ Period II (in 2011) } & $-0.0121^{* * *}$ & $-0.0162^{* * *}$ & $-0.0104^{* * *}$ & $-0.0160^{* * *}$ \\
\hline & $(0.0008)$ & $(0.0014)$ & $(0.0009)$ & $(0.0033)$ \\
\hline \multirow[t]{2}{*}{ Period III (in 2011) } & -0.0003 & -0.0027 & 0.0005 & -0.0013 \\
\hline & $(0.0009)$ & $(0.0017)$ & $(0.0011)$ & $(0.0041)$ \\
\hline \multirow[t]{2}{*}{ Period IV (in 2011) } & $-0.0097^{* * *}$ & $-0.0137^{* * *}$ & $-0.0081^{* * *}$ & $-0.0131^{* * *}$ \\
\hline & $(0.0008)$ & $(0.0014)$ & $(0.0010)$ & $(0.0034)$ \\
\hline \multirow[t]{2}{*}{ Year 2012} & -0.0007 & -0.0014 & -0.0004 & -0.0021 \\
\hline & $(0.0009)$ & $(0.0017)$ & $(0.0011)$ & $(0.0040)$ \\
\hline \multirow[t]{2}{*}{ Year $2012 \times$ Period II } & -0.0002 & 0.0010 & -0.0009 & 0.0003 \\
\hline & $(0.0011)$ & $(0.0019)$ & $(0.0012)$ & $(0.0046)$ \\
\hline \multirow[t]{2}{*}{ Year $2012 \times$ Period III } & 0.0004 & 0.0002 & 0.0006 & 0.0029 \\
\hline & $(0.0013)$ & $(0.0023)$ & $(0.0016)$ & $(0.0058)$ \\
\hline \multirow[t]{2}{*}{ Year $2012 \times$ Period IV } & -0.0002 & -0.0007 & 0.0002 & 0.0027 \\
\hline & $(0.0011)$ & $(0.0020)$ & $(0.0013)$ & $(0.0049)$ \\
\hline \multirow[t]{2}{*}{ Constant } & $0.0184^{* * *}$ & $0.0258^{* * *}$ & $0.0150^{* * *}$ & $0.0237^{* * *}$ \\
\hline & $(0.0007)$ & $(0.0012)$ & $(0.0009)$ & $(0.0029)$ \\
\hline Observations & 468,243 & 160,025 & 308,218 & 21,459 \\
\hline
\end{tabular}

Note: ${ }^{*} \mathrm{p}<.10 * * \mathrm{p}<.05 * * * \mathrm{p}<.01$. Standard errors clustered for employer in brackets. In period IV those who had an eligible colleague during period III (of the same year) are considered as having an eligible colleague as well.

incentives. Column (3) in Table 5 repeats the exercise for this group, while column (4) is further limited to the cases where there is only one eligible colleague. ${ }^{20}$ The change in the across period pattern is still very close to zero and statistically not significant. For completeness, Table 6 shows some closely related placebo regressions: we still focus only on individuals aged 30 or more, but we define as "treated" those with an eligible colleague. We focus on single periods, and we use 2011 as pre-policy and 2012 as afterpolicy. Again, all interactions are precisely estimated zeros. ${ }^{21}$

Table 6 Test for a reduction in the control group: change in conversion rate between 2011 and 2012, only men $\geq 30$ with eligible colleagues

\begin{tabular}{lllll}
\hline Dep. var.: dummy for conversion & Men $\geq \mathbf{3 0}$ & & \\
\cline { 2 - 5 } & Period I & Period II & Period III & Period IV \\
\hline Year 2012 & -0.0014 & -0.0004 & -0.0013 & $-0.0021^{*}$ \\
& $(0.0017)$ & $(0.0010)$ & $(0.0016)$ & $(0.0011)$ \\
$\mathbf{1}$ [with eligible colleagues] & $-0.0108^{* * *}$ & $-0.0050^{* * *}$ & $-0.0075^{* * *}$ & $-0.0052^{* * *}$ \\
& $(0.0015)$ & $(0.0009)$ & $(0.0015)$ & $(0.0010)$ \\
Year 2012× 1[with eligible colleagues] & 0.0010 & -0.0009 & 0.0015 & 0.0019 \\
& $(0.0020)$ & $(0.0011)$ & $(0.0020)$ & $(0.0014)$ \\
Constant & $0.0258^{* * *}$ & $0.0096^{* * *}$ & $0.0230^{* * *}$ & $0.0121^{* * *}$ \\
& $(0.0012)$ & $(0.0007)$ & $(0.0012)$ & $(0.0008)$ \\
Observations & 131,050 & 116,164 & 115,086 & 105,943 \\
\hline
\end{tabular}

Note: ${ }^{*} p<.10 * * p<.05{ }^{* * *} p<.01$. Standard errors clustered for employer in brackets. In period IV those who had an eligible colleague during Period III (of the same year) are considered as having an eligible colleague as well. 
Another possible substitution could take place between conversions (from fixed-term to permanent positions) and direct hires with a permanent contract. In Figure 4 we show the time series of the daily difference between the number of direct hires with a permanent contract in 2012 and in 2011, for different groups. There is no evidence of a change in the number of direct hires during the period of validity of the policy.

A related concern is that firms could have simply hired individuals under fixed-term contracts during Periods II or III and converted them shortly after in order to benefit from the incentives. However, only $3.8 \%$ of the converted contracts for eligible individuals in Period III had lasted less than a month at the time of conversion. Furthermore, if this had been the case, all the effects should have come from job-relationships started after the announcement of the policy. We reproduced our main regressions by keeping a "closed" sample composed only of fixed-term contracts started in Period I
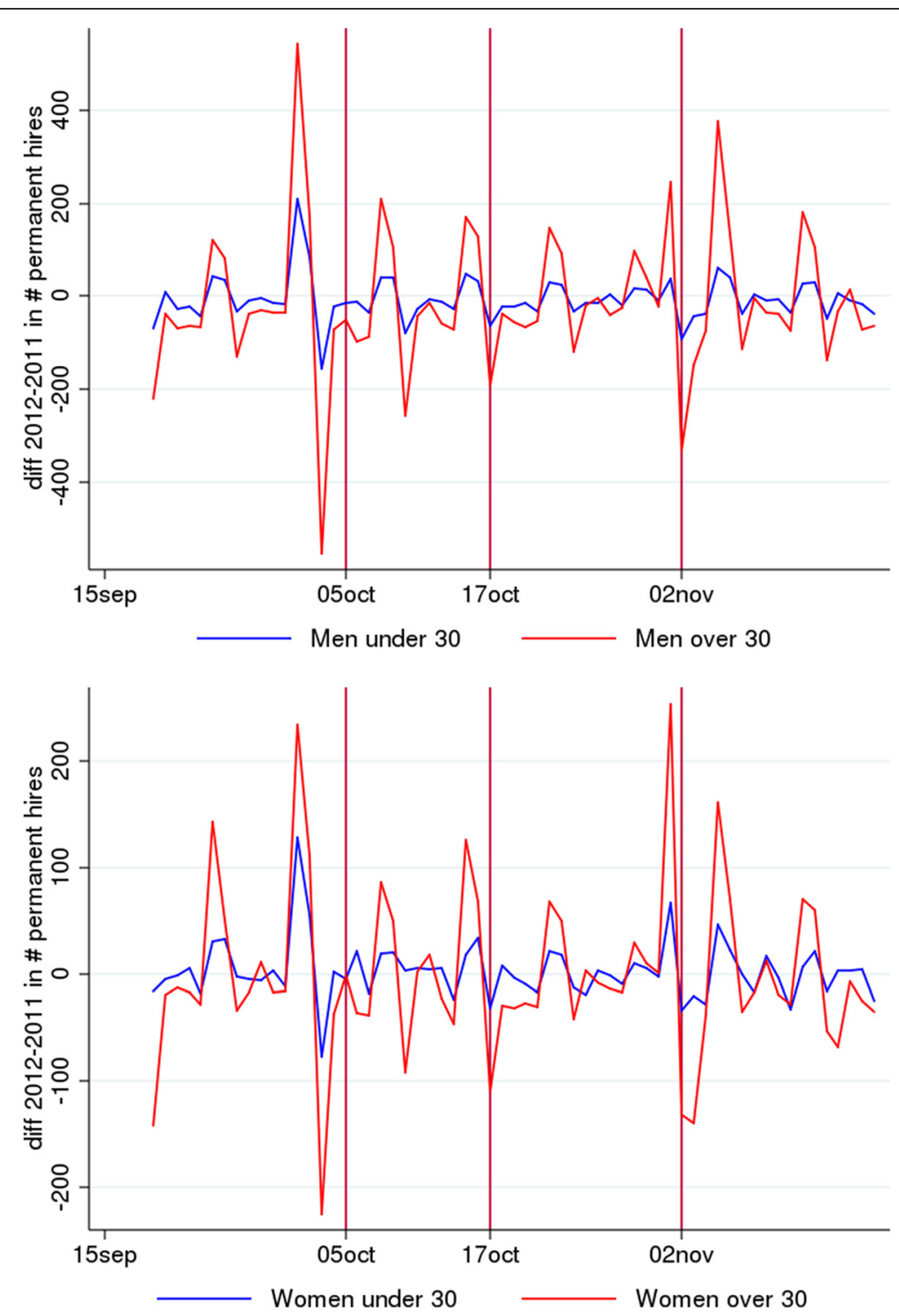

Figure 4 Number of direct hires in 2012 vs 2011; Difference in the number of direct hires with permanent contracts between 2012 and 2011, by day and group. 
or earlier (Table 4, column (5)). Results are reassuring and very similar to those already discussed.

Incentives for converting a contract may be substantially different depending on the duration of the job-relationship. Although the estimates with covariates already include the elapsed duration in days as a control, an alternative would be to specify a duration model. Given that our smallest time unit is the day, we rearrange our panel into jobrelationship - day observations, and we focus on the daily probability of conversion. In each day, contracts that are still active as fixed-term have $y_{i t}=0$ (here, the time subscript $t$ refers to days), while those that get converted have $y_{i t}=1$ and exit the sample after the conversion. Essentially, we rearrange the sample as a typical case of stock sampling for the estimation of a discrete-hazard model.

Using this sample, we first re-estimate the main linear dif-in-dif model (as in Table 1, column (1)) on this new sample. Unsurprisingly, the results are very similar, with a statistically significant increase in the daily probability of conversion for the eligible group of 0.09 percentage points during Period III, which is equal to 80.5 percent of the counterfactual rate (see Additional file 1 for full results).

We then estimate a simple discrete-hazard model using a logit (common in the literature) but specifying the index as in the dif-in-dif specification plus the log of the elapsed duration (in days) as an additional covariate. We also include a full set of interactions between duration and the eligible period and the eligible $\times$ period interaction dummies in order to allow for heterogeneity in the policy effect by duration. ${ }^{22}$ This is important to also address the fact that with stock-sampling there is a potential problem of under-representation of short-lasting job-relationships. Due to lack of space, graphs showing the predicted daily rate of conversion by contract duration and the relative counterfactual rate are reported in the Additional file 1. Results are in line with those from our main regression: the conversion rate, in this case expressed on a daily basis, increases for the eligible group with respect to the counterfactual rate in Period III, while no statistically significant change is found in the other periods. The effect is present for all durations. In absolute value, it is greater for older contracts, but overall the change associated with the policy can be seen as a shift upward of the curve of daily conversion rates with respect to elapsed duration. Similar results hold if we use dummies for elapsed duration in quarters as a covariate instead of the log of elapsed duration in days.

Given that an effect is also found for relatively younger contracts, we worried that the effects of anticipation on the conversion rates of eligible workers could be found later than Period IV, which also does not include the beginning of a month. In extending the time period, there is a trade-off between the likelihood that the parallel trend assumptions still hold and the possibility that substitution effects take place later in time. We tried to balance the two by adding four subsequent periods of 16-days, hence plugging in dates until January 21st. The results are reassuring (see Additional file 1). Although the estimates for the interaction term with the last two periods is negative, these are due to different seasonal trends as they are also present in the falsification over 2011, with very similar magnitude and standard errors. Indeed, if we remove them by running a triple-difference regression, there is no evidence of an additional effect of the policy in any of the groups. Similar results hold with a "closed" sample of contracts signed before the policy was announced. These results on the following period are also 
important to address another concern: that the positive results in Period III may be explained by the progressive selection of the best-performing firms during the ongoing economic crisis. If this was true, we should find positive effects also in December 2012 and early January 2013.

Additional robustness tests have also been implemented. For instance, a possible difficulty is related with the circumstance that, for bureaucratic reasons, conversions are more likely at the turn of a month. In our case, however, the effect is not driven by conversions taking place at the end of October or beginning of November: excluding the days [31/10-02/11], we still find evidence of an impact for the eligible group (see Additional file 1). Finally, the incentives for conversions could be cumulated with others available for hiring workers that have been previously dismissed through a particular procedure called mobilità. We also replicated all our regressions by excluding these employees, again with no significant changes in the findings (see Additional file 1).

\subsection{Heterogeneity}

The results documented so far for the groups of eligible workers might mask relevant heterogeneities. An important issue refers to the impact of the scheme across individuals with different education. For instance, a policy maker might want to know whether the program works for those who are less endowed with human capital, as their performance in the labor market is usually more problematic. In the following, for simplicity, we only focus on the effects that materialize in Period III.

Figure 5 shows, for the eligible groups taken as a whole, the breakdown by educational level of the estimated effect (measured in percentage points on the left and as a proportion of the counterfactual rate on the right). ${ }^{23}$ The impact of the scheme seems to be less for those who have at most completed primary school. However, this is a relatively small group, accounting for only $10.7 \%$ of the observations for eligible workers in 2012. Differently, starting from middle school ( $8^{\text {th }}$ grade), there is no evidence of strong heterogeneity: most of the effects are positive, and there is no systematic increase associated with higher qualifications. Furthermore, the effects are all
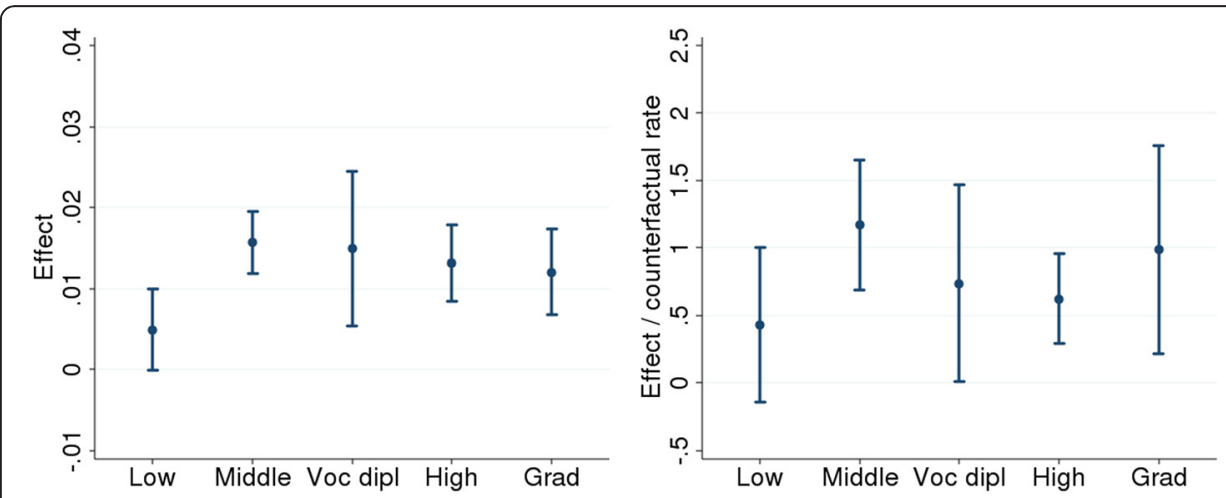

Figure 5 Dif-in-dif by educational level; Effect on the rate of conversion for the entire eligible group during Period III, in absolute value on the left and as a proportion of the counterfactual rate on the right; $95 \%$ confidence interval with s.e. clustered by employer; "Low" stands for workers who completed at most primary school, "Middle" is the 8th grade, "Voc Dipl" is a vocational diploma course that lasts two or three years after middle school, "High" is for high school, "Grad" stands for university graduates. 
significantly different from zero at the $5 \%$ level. Similar conclusions can be reached by looking at the proportional effect, although it must be considered that these estimates are less precise due to the fact that even the baseline rate of conversion is estimated through the same model. The results obtained by breaking down the educational levels for each single group (young men, young women, and older females) of eligible workers are qualitatively similar (and available on request). One potential concern is that the reduction in the number of observations, and in particular in the total number of observed conversions, for each cell of group $\times$ period $\times$ educational qualification makes estimates largely imprecise, making it difficult to detect heterogeneity. To allay this concern, we also estimated the average effects using only low qualifications (middle school or less) on the one hand, and high qualifications (high school or above) on the other. ${ }^{24}$ Results are only marginally modified: the $95 \%$ confidence interval for the effect in percentage points is $[.0098 ; .0161]$ for low qualifications, which is very similar to that estimated for the other group, $[.0089 ; .0163] .{ }^{25}$ Overall, it seems safe to conclude that the impact of the scheme was quite homogeneous across groups with different education.

It is also interesting to check to what extent the scheme impacted firms with different compositions of their workforce in terms of contractual agreements. For instance, because of the specific features of their production, some firms might be less interested in signing permanent contracts no matter what incentives they could receive. On the other hand, other firms might use short-term positions as a temporary step to bring their workers into the permanent pool. In this latter case, at any point in time, the firms will have many open-ended positions and only a few fixed-term appointments (which will later expire or be converted). Figure 6 breaks down the impact of the program by the number of fixed-term contracts referring to the same employer (again, measured both in percentage points and as a proportion of the baseline rate of conversion). ${ }^{26}$ The evidence suggests that the effect is less for workers whose employers hold a larger number of fixed-term contracts. ${ }^{27}$ A statistical test on the equality of the effects across the different categories of firms rejects the null at the $5 \%$ level, considering both the effects in percentage points ( $\mathrm{p}$-value 0.000 ) and as a proportion of the baseline (p-value 0.002). One important caveat is that the scheme has a limit of 10 incentives

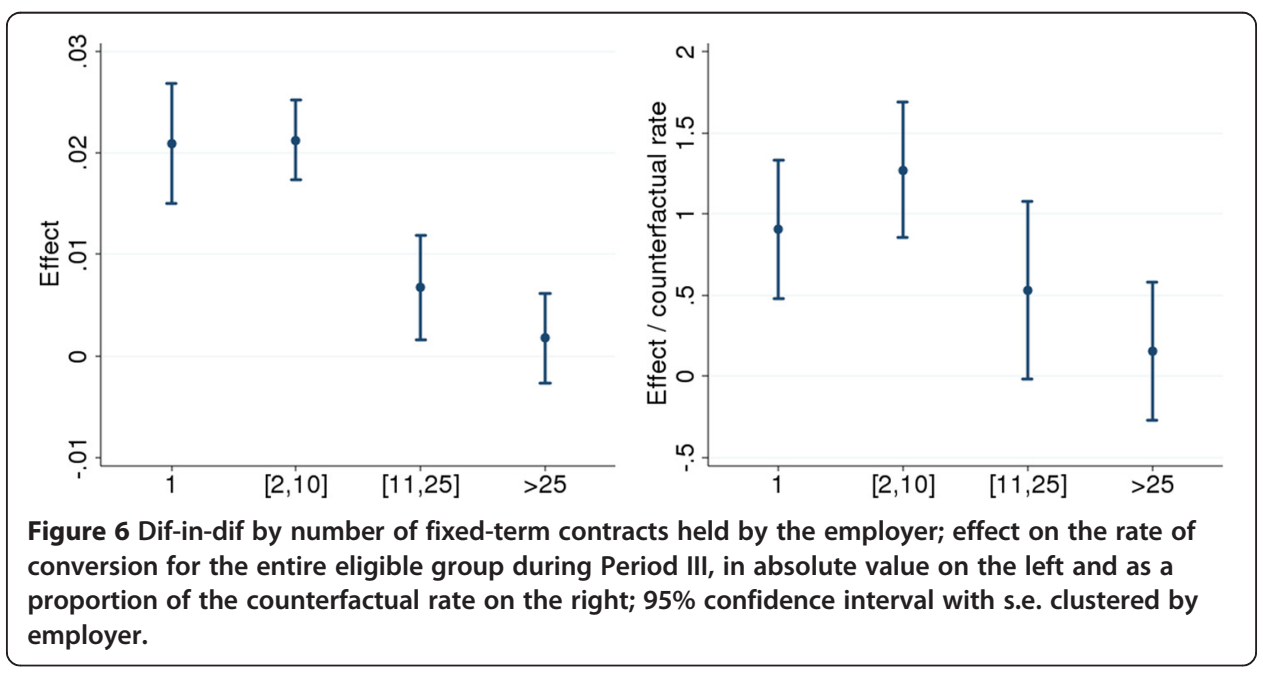


per employer (see Section 2), which limited the possibilities of conversion for workers with many colleagues holding fixed-term contracts. ${ }^{28}$

\subsection{Effects on permanent employment}

Finally, we double-check our findings by looking at the effects of the program on permanent employment measured up to 7.5 months after the end of Period III. The magnitude of the financial incentives could have induced firms to convert short-term positions into permanent contracts only to obtain the assignment and later dismiss the workers as soon as the six-month duration requirement was met. Although the possibility of this strategic behavior is limited by the presence of higher EPL for permanent workers, a fraction of subsidized conversions may have occurred in small enterprises, for which EPL is lower. ${ }^{29}$

Our test is the following. We switch our focus from job-relationships to individuals and keep only those who held a standard fixed-term contract in Period III. Next, we see whether, among this sample, those eligible for the incentives were more likely to be in a permanent position (not necessarily with the same employers, as they may access permanent employment also by applying to other employers) during the following months; we use February, April and June 2013 (the last date of availability of our data). We implement once more a diff-in-diffs approach and use as pre-policy counterfactuals the individuals who held fixed-term contracts in the 2011 period analogous to Period III, for which their employment status is measured during the first semester of 2012. Formally, we estimate a diff-in-diffs regression of the type:

$$
\mathrm{y}_{\mathrm{it}}=\lambda_{0}+\lambda_{\mathrm{E}} \mathbf{1}[\text { Eligible }]_{\mathrm{it}}+\lambda_{2012} \mathbf{1}[\text { year 2012 }]_{\mathrm{it}}+\theta \mathbf{1}\left[\text { Eligible }_{\mathrm{it}} \times \mathbf{1}[\text { year 2012 }]_{\mathrm{it}}+\mu_{\mathrm{it}}\right.
$$

Table 7 describes the results. In the first panel, Column (1) describes the estimates of the probability of conversion during Period III. Columns (2), (3) and (4) provide the estimates of the chance of being in permanent employment in the following months. Our evidence suggests a significant increase in the probability of conversion (at the individual level) in Period III (the magnitude of the effect is larger, but compatible with the results where the unit of observation is job-relationship). We also find positive and statistically reliable effects as to the likelihood of being permanent in February, April and June 2013. Note that the point estimates for the impact on permanent employment later in time are smaller than the increase in conversion probability in Period III. Although the difference is statistically significant at the $5 \%$ level only in one case (April), this finding could mean that a fraction of the subsidized conversions went to individuals who would have accessed permanent employment even in the absence of the incentives.

However, we have to make sure that the eligible group does not show a diverging trend in the probability of accessing permanent employment during the first semester of 2013. In the second panel of Table 7, we run a falsification exercise by focusing on individuals holding a fixed-term contract in the following month, between 17/11 and 2/ 12. As we have already explained, in this period incentives were not available anymore. According to our evidence of no substitution over time, we do not expect these individuals to be affected by the policy. Indeed, column (1) of the second panel in Table 7 shows that there is no effect on the conversion rate of eligible individuals in this period. 
Table 7 Regressions for the probability of being in permanent employment some months later; individuals holding a fixed-term contract in a specific period

\begin{tabular}{|c|c|c|c|c|}
\hline \multirow{4}{*}{$\begin{array}{l}\text { Control group: Men } \geq 30 \\
\text { Treatment group: all eligibles }\end{array}$} & \multicolumn{4}{|l|}{ Dependent variable } \\
\hline & $(1)$ & $(2)$ & (3) & (4) \\
\hline & \multirow[t]{2}{*}{$\begin{array}{l}\text { Dummy for contract } \\
\text { conversion in the initial period }\end{array}$} & \multicolumn{3}{|c|}{$\begin{array}{l}\text { Dummy for permanent employment } \\
\text { on the 15th of the following: }\end{array}$} \\
\hline & & February & April & June \\
\hline & \multicolumn{4}{|c|}{ Individuals with a fixed-term contract in period III (in 2011 or 2012) } \\
\hline \multirow[t]{2}{*}{ Eligible } & $-0.0037^{* * *}$ & $-0.0367^{* * *}$ & $-0.0420^{* * *}$ & $-0.0498^{* * *}$ \\
\hline & $(0.0009)$ & $(0.0029)$ & $(0.0034)$ & $(0.0037)$ \\
\hline \multirow[t]{2}{*}{ Year 2012} & -0.0003 & 0.0036 & 0.0017 & -0.0042 \\
\hline & $(0.0010)$ & $(0.0030)$ & $(0.0033)$ & $(0.0034)$ \\
\hline \multirow[t]{2}{*}{ Eligible $\times$ Year 2012} & $0.0152^{* * *}$ & $0.0110^{* * *}$ & $0.0078^{* *}$ & $0.0089^{* *}$ \\
\hline & $(0.0013)$ & (0.0035) & (0.0038) & $(0.0040)$ \\
\hline \multirow[t]{2}{*}{ Constant } & $0.0187^{* * *}$ & $0.1701^{* * *}$ & $0.2103^{* * *}$ & $0.2425^{* * *}$ \\
\hline & $(0.0007)$ & $(0.0025)$ & $(0.0029)$ & $(0.0032)$ \\
\hline Observations & 284,012 & 284,012 & 284,012 & 284,012 \\
\hline \multicolumn{2}{|c|}{ Test for equality of interaction term with column (1) } & 0.2075 & 0.0428 & 0.1027 \\
\hline & \multicolumn{4}{|c|}{ Falsification using period [17/11 - 2/12] (in 2011 or 2012) } \\
\hline \multirow[t]{2}{*}{ Eligible } & $-0.0040^{* * *}$ & $-0.0342^{* * *}$ & $-0.0402^{* * *}$ & $-0.0492^{* * *}$ \\
\hline & $(0.0008)$ & $(0.0029)$ & $(0.0034)$ & $(0.0038)$ \\
\hline \multirow[t]{2}{*}{ Year 2012} & -0.0001 & $0.0092^{* * *}$ & $0.0083^{* *}$ & 0.0023 \\
\hline & $(0.0009)$ & $(0.0033)$ & $(0.0036)$ & $(0.0037)$ \\
\hline \multirow[t]{2}{*}{ Eligible $\times$ Year 2012} & 0.0003 & -0.0056 & $-0.0091^{* *}$ & $-0.0078^{*}$ \\
\hline & $(0.0011)$ & $(0.0037)$ & $(0.0041)$ & $(0.0044)$ \\
\hline \multirow[t]{2}{*}{ Constant } & $0.0157^{* * *}$ & $0.1609^{* * *}$ & $0.2074^{* * *}$ & $0.2460^{* * *}$ \\
\hline & $(0.0006)$ & $(0.0025)$ & $(0.0028)$ & $(0.0033)$ \\
\hline Observations & 244,950 & 244,950 & 244,950 & 244,950 \\
\hline \multicolumn{2}{|c|}{ Test for equality of interaction term with column (1) } & 0.1028 & 0.0199 & 0.0592 \\
\hline & Triple difference & & & \\
\hline \multirow[t]{2}{*}{ Eligible } & $-0.0040^{* * *}$ & $-0.0342^{* * *}$ & $-0.0402^{* * *}$ & $-0.0492^{* * *}$ \\
\hline & $(0.0008)$ & $(0.0029)$ & $(0.0034)$ & $(0.0038)$ \\
\hline \multirow[t]{2}{*}{ Year 2012} & -0.0001 & $0.0092^{* * *}$ & $0.0083^{* *}$ & 0.0023 \\
\hline & $(0.0009)$ & $(0.0033)$ & $(0.0036)$ & $(0.0037)$ \\
\hline \multirow[t]{2}{*}{ Eligible $\times$ Year 2012} & 0.0003 & -0.0056 & $-0.0091^{* *}$ & $-0.0078^{*}$ \\
\hline & $(0.0011)$ & $(0.0037)$ & $(0.0041)$ & $(0.0044)$ \\
\hline \multirow[t]{2}{*}{ Period III } & $0.0030^{* * *}$ & $0.0092^{* * *}$ & $0.0029^{* *}$ & $-0.0035^{* *}$ \\
\hline & $(0.0009)$ & $(0.0012)$ & $(0.0013)$ & $(0.0014)$ \\
\hline \multirow[t]{2}{*}{ Period III $\times$ Eligible } & 0.0003 & $-0.0025^{*}$ & -0.0018 & -0.0006 \\
\hline & $(0.0011)$ & $(0.0014)$ & $(0.0015)$ & $(0.0016)$ \\
\hline \multirow[t]{2}{*}{ Period III × Year 2012} & -0.0002 & $-0.0056^{* * *}$ & $-0.0067^{* * *}$ & $-0.0065^{* * *}$ \\
\hline & $(0.0013)$ & $(0.0014)$ & $(0.0014)$ & $(0.0015)$ \\
\hline \multirow[t]{2}{*}{ Period III X Eligible X Year 2012} & $0.0149^{* * *}$ & $0.0166^{* * *}$ & $0.0169^{* * *}$ & $0.0166^{* * *}$ \\
\hline & $(0.0017)$ & $(0.0017)$ & (0.0018) & (0.0018) \\
\hline \multirow[t]{2}{*}{ Constant } & $0.0157^{* * *}$ & $0.1609^{* * *}$ & $0.2074^{* * *}$ & $0.2460^{* * *}$ \\
\hline & $(0.0006)$ & $(0.0025)$ & $(0.0028)$ & $(0.0033)$ \\
\hline Observations & 528,962 & 528,962 & 528,962 & 528,962 \\
\hline Test for equality of triple interacti & n term with col (1) & 0.3105 & 0.2787 & 0.3631 \\
\hline
\end{tabular}

Note: ${ }^{*} p<.10{ }^{* *} p<.05{ }^{* * *} p<.01$. Standard errors clustered for employer in brackets. 
We can therefore use this group to infer whether eligible workers would have shown a diverging trend in the absence of the incentives. If there is evidence of a downward trend (with respect to men over 30) in the probability of getting a permanent job, we would be underestimating the effects of the incentives. In columns (2)-(4) of the second panel, we find that the probability of being in permanent employment later in time (in April and June) decreases by around 0.8-0.9 percentage points for eligible workers. Note that this gap is similar to the difference between the effect on conversion and that on permanent employment documented in the first panel.

Therefore, we find evidence of a diverging negative trend for the eligible group. In order to correct it, the third panel runs a triple difference regression, which is simply equivalent to subtracting panel 2 from panel 1 . The effect of the policy is now captured by the coefficient on the triple difference Period III $\times$ Eligible $\times$ Year 2012. The point estimates for employment are now quite stable over time and comparable with the conversion rate, although slightly larger.

We also did an additional check. We replicated the second and third panel of Table 7 by removing from the group of individuals holding a fixed-term contract between 17/ 11 and 2/12 those hired by firms that had previously had a conversion in Period III. This should minimize the risk of substitution over time and across workers because it excludes those employers who could have strategically anticipated conversions during Period III. The results, available in the Additional file 1, are in line with those presented here.

All in all, our findings suggest that the impact on permanent employment is still there 7.5 months after the scheme has ended. More generally, this shows that the individuals who benefited from the increased conversion rate would not have found a permanent job in the absence of the policy. Nevertheless, part of the stability of the effect over time may be due to the fact that the incentives were distributed only on condition that the contract would last at least six months after the conversion.

\section{Comparison with a previous Italian policy}

A previous and related policy was introduced at the beginning of the last decade. A comparison with it is useful to indicate which features may hinder or increase the effectiveness of these schemes.

In the year 2000, Law 388 established a tax-credit of 413 euros per month (620 in the South of Italy) for each unit increase in the number of permanent workers aged 25 or more with respect to the average reported for the pre-policy year. The scheme also required employers to increase the overall workforce. Essentially, employers could access the incentive by hiring a new worker with a permanent contract or by converting a fixed-term one but simultaneously also hiring a new temporary (or permanent) worker. ${ }^{30}$ In both cases the new hire could not be simply a substitute for another employee ceasing his/her contract (due to retirement, dismissal, or for any other reason) because the overall number of employees had to increase. ${ }^{31}$ The tax-credit was quite extensive in time, as it was supposed to last until the end of 2003, and it was later extended until 31/12/2006 by law 289/2002. This policy was evaluated by Cipollone and Guelfi $(2003,2006)$, who estimated its impact on the probability that individuals would enter into permanent employment using longitudinal data from the Labor Force Survey. Although they found no aggregate effect, they provided evidence of a positive effect 
for more educated workers, in particular university graduates. This is coherent with a model where individual productivity is unknown to the employer, who therefore prefers to hire permanently only individuals with a strong sign of higher productivity. They also found that the effect of the incentives on the probability of getting a permanent job was higher for those who were employed with a temporary training contract in the previous year (not necessarily with the same employer) and for those who were unemployed but had previous work experience.

Differently from them, we found an aggregate positive effect, and we did not find sensible differences according to the educational level of the worker. One reason is that the general results of Cipollone and Guelfi (2006) refer to the probability of entering permanent employment from any other status, while we analyzed the effect only on the conversion rates from fixed-term to open-ended contracts. Indeed, our results are consistent with their finding of a positive effect for those previously employed with a temporary training contract, suggesting that these incentives may be more likely to have an impact on conversions rather than on new hires. This could also explain the absence of heterogeneity by educational level in our estimates. While they correctly argued that a potential employer is more likely to exploit an incentive in order to directly hire individuals with signs of higher productivity (in particular for more educated workers), this framework is not the best for discussing the effect of the benefits for contract conversions introduced by the 5 October 2012 Decree. The reason is that in this case, all the eligible workers were already known by the employer, who had already had time to screen them during the fixed-term contract; therefore their willingness to change their status to permanent is less likely to depend on signs of external productivity.

Another important difference between the policy set up by law 388/2000 and the one we studied is that it required the employer to increase the workforce, which can be particularly crucial during an economic crisis. Clearly, whether a policy maker should impose or not this additional constraint also depends on the final target of the scheme, which may aim at increasing overall employment and not only the rate of conversion. Furthermore, caution is necessary here before drawing any conclusions because we did not simultaneously observe the two alternative treatments, with and without the constraint, and therefore further evidence is needed to evaluate whether it played an important role.

\section{Conclusions}

Our exercise suggests that the program introduced by the 5 Oct 2012 Decree was effective in stimulating conversions. Compared to the counterfactual scenario, conversions increased by $83 \%$. The additional permanent positions came with a cost: to get one extra permanent job, the government had to finance an additional 1.2 conversions that would have taken place even without public support.

There is no need to say that the external validity of the experiments to evaluate the program is wanting. Thus, it is not safe to infer from our results generally valid policy implications relative to the effectiveness of conversion programs. Having said this, a number of remarks are in order.

First, the scheme we evaluated shows little sign of perverse conduct by employers. There is no evidence of strategic behavior intended to bring conversions forward or backward only to benefit from the scheme. This circumstance might well be explained 
by the short span of time between announcement and beginning of the program and by the fact that the shortage of financing might have come earlier than expected (by the employers).

Secondly, it is very difficult to say whether the amount of the subsidy was appropriate for converting the greatest possible number of short-term positions. Although higher financial support could have spurred additional conversions at the same time, this would have increased the financial dead-weight loss associated with the conversions that would have occurred even without the scheme. Therefore, within the budget constraints envisaged by 5 Oct 2012 Decree, increasing the subsidy might not necessarily have helped convert more contracts. If one believes that the employers' demand for conversions was fully satisfied at the established amount, then it is not unrealistic to say that a smaller amount of money could have achieved a similar effect.

Finally, the comparison with the previous tax-credit set up by Law 388/2000 suggests that incentives for conversions may be more effective than general benefits for hires on a permanent contract basis because they exploit the stepping-stone effect of fixed-term contracts. At the same time, the previous policy may have had a slighter aggregate effect because it imposed the constraint that the employer had to also increase the overall workforce. Nevertheless, whether to impose this requirement or not depends on the target of the scheme: a policy maker may be more interested in increasing employment than in reducing instability.

\section{Endnotes}

${ }^{1}$ In particular, Méndez (2013) criticizes the assumption of Hernanz et al. (2003) that individuals aged between 30 and 45 could not be hired with the new open-ended contracts. According to Méndez (2013), this is not correct because they actually could if they had been previously hired as fixed-term workers.

${ }^{2}$ In 2002 Portugal introduced a scheme of incentives for the conversion of temporary contracts, but to the best of our knowledge no study has evaluated its effects.

${ }^{3}$ Note that the program did not introduce any constraint as to the variation in total workforce following the conversions/stabilizations.

${ }^{4}$ There are a few exceptions that involve a small number of workers, in particular contracts for directors that could be signed for 5 years. However, our data are based on a region that had already been collecting the data for several years before 2008, and therefore we should be able to observe almost all relevant contracts in 2011 and 2012.

${ }^{5}$ This selection clears possible distortions generated by the specificity of these contracts. Among eligible fixed term workers in the selected periods in 2012, 71.9\% had standard contracts, and they represented $90.7 \%$ of the contracts that were converted into permanent ones. Our main results carry through to the more general case, where all these nonstandard contracts are kept in the dataset (apart from those signed with a temporary employment agency, which were not eligible for the incentive); in this case the point estimate is smaller, but it is quite close to our main results if measured as a proportion of the counterfactual. Our findings are also indistinguishable if the public sector is dropped from the sample. See Additional file 1 for these results.

${ }^{6} \mathrm{We}$ use the information on the educational level in the most recent communication regarding fixed-term contracts (before the conversion, in case that takes place).

${ }^{7}$ We censor to 5 years $0.5 \%$ of the observations which have a longer elapsed duration. 
${ }^{8}$ In the specific case, as discussed in the Section 2, some of the firms who made a conversion expecting to receive the benefit were later excluded on a first come first served basis. As mentioned, they could not make completely sure that the money was available for them at the moment of the application, and they could not cancel the conversion if they found out later on that they were excluded. Therefore, the total number of subsidies can be lower than the total number of conversions. But this does not prevent us from estimating the effect of the change in incentives on the rate of conversion by focusing on the eligibility status.

${ }^{9}$ For a discussion of announcement and implementation effects in diff-in-diffs analysis, see Blundell et al. (2011).

${ }^{10} \mathrm{We}$ also replicated the estimates defining the age as referring to the end of the period (see Additional file 1), with no sensible changes for the results.

${ }^{11}$ We always use standard errors clustered at the employer level to account for potential common shocks across different job-relationships. We also tried using standard errors clustered by sector of economic activity: all the main results continued to show statistical significance (see Additional file 1).

${ }^{12}$ We also do not know the total amount of incentives distributed for conversions in the Veneto region only and precisely during Period III.

${ }^{13}$ In the calculation we do not account for the possible presence of an effect in Period IV as well because any effect could come from a diverging trend for older women, and its impact is anyway quite insignificant.

${ }^{14}$ This value is similar to the one that can be obtained by dividing the total amount spent in Italy by the total number of incentives distributed using the info available from the Ministry of Labor (Ministero del Lavoro e delle Politiche Sociali 2013).

${ }^{15} \mathrm{We}$ could have used previous years as well. Clearly, if the underlying seasonal trends did not have any evolution over time, this could allow us to estimate them more precisely and increase the power in detecting deviations during 2012. However, we do not expect full comparability over time, also because of the ongoing economic crises, and therefore we preferred to limit the falsification only to the previous year. This is also motivated by a question of data tractability, given that the size of the microdata generated from the administrative archives is quite demanding in terms of memory requirement and processing time.

${ }^{16}$ One could also combine the falsification over 2011 and the main estimates over 2012 to obtain triple-difference estimates. We also run this joint regression, obtaining results that are qualitatively similar and support our conclusions. However, given that in 2011 the interaction terms are generally economically small and not statistically significant, we prefer to focus on the diff-in-diffs within 2012 in order to avoid introducing noise into our main estimates.

${ }^{17}$ Younger men and women may also move across groups if they turn old (according to our grouping) during the period of the analysis. Given the limited time span we focus on, this is not likely to be a major concern.

${ }^{18}$ In the case of lacking educational level, we kept the observation but we added a dummy for the missing value. For the sector of activity, there are only 4 missing values in 2011 that we excluded.

${ }^{19}$ We also conducted a falsification exercise by using only men aged 30 or over and splitting them into a "fake eligible group" aged $[30,40)$ and a control group aged $40+$. 
We do not find evidence of an effect of the policy. Note also that if our estimates were biased by the fact that during the ongoing economic crises older workers are progressively more likely to keep their job, then we should have also found evidence of diverging trends between these two sub-groups of controls.

${ }^{20}$ To account for the fact that contracts exit the sample in the period after they are converted, in Period IV we considered as having an eligible colleague also those who had an eligible colleague in Period III of the same year.

${ }^{21}$ We also did the same regression adding four other periods of 16 days at the end. Interactions are still close to zero and not statistically significant.

${ }^{22} \mathrm{~A}$ complete model would also account for the fact that contracts may terminate by estimating a multinomial logit model that accounts for competing risks. We also did that, finding virtually the same results for conversion rates. We also found that the effect seems to come mostly from a reduction in termination rates. However, we prefer not to stress this additional result, which goes beyond the purpose of the current work and would require further examination. This is also because the effect on termination rates is more likely to be spread throughout following periods as well.

${ }^{23}$ The information on educational qualifications is reported by the employer at the time of communication to the regional agency. There are $0.7 \%$ of the observations with missing values. Given that for foreign citizens this information is likely to contain measurement errors, we also reproduced the graph considering only Italian citizens, but we found no qualitative differences. It must also be added that the falsification over 2011 fails to reject the null that interaction terms Eligible $\times$ Period III in all educational groups are jointly equal to zero, with a p-value of 0.1461 .

${ }^{24} \mathrm{We}$ did not consider vocational diplomas, which occupy a particular position between low and high qualifications. Nevertheless, they involve only around $5.5 \%$ of the eligible observations, and the effect for them is similar to the one for high school graduates.

${ }^{25}$ Given that the baseline rate of conversions is higher for the most educated, these results imply a smaller percentage increase for them, although we still fail to reject the null that the proportional effect is different (with high p-values).

${ }^{26}$ Running a falsification exercise over 2011 fails to reject the null that interaction terms Eligible $\times$ Period III in all numbers of fixed-term contract categories are jointly equal to zero, with a p-value of 0.5872 .

${ }^{27}$ As a side-line, results for firms with only one fixed-term contract are an additional robustness check, given that employers could not substitute between eligible and not eligible workers.

${ }^{28} \mathrm{We}$ also split the sample according to the number of eligible fixed-term workers. We found that the impact is positive and statistically significant only for employers with at most 10 eligible workers; for firms having more than 10 eligible workers, the impact remains positive (though smaller) and not statistically significant at the $5 \%$ level.

${ }^{29}$ As mentioned in Section 3, our dataset does not allow us to recover the size of the firm's workforce. Therefore, we cannot estimate the percentage of small firms among all contract conversions in Period III. Nevertheless, in Section 5.3 we showed that the effect was stronger in firms with 1 or 2 fixed-term employees; such firms are likely to be, on average, smaller.

${ }^{30}$ To be eligible, individuals hired with (or converted to) permanent contracts should not have held another open-ended contract in the previous 12 months. 
${ }^{31}$ The actual calculation of the increase in employment depended also on the length of the contract because fixed-term contracts lasting less than 12 months counted also as a fraction of the entire year. Therefore, it was formally possible to increase employment by simply transforming a 6 month fixed-term contract (counting 6/12) into a permanent one $(12 / 12)$.

\section{Additional file}

Additional file 1: Contains additional results and descriptive statistics.

\section{Competing interests}

The IZA Journal of European Labor Studies is committed to the IZA Guiding Principles of Research Integrity. The authors declare that they have observed these principles.

\section{Acknowledgements}

We wish to thank Bruno Anastasia and the staff at Veneto Lavoro (in particular Sebastiano Basso and Gianluca Emireni) for granting us access to the dataset and for providing excellent support in understanding its technicalities. We are also indebted to Anna Giraldo, Adriano Paggiaro, Sauro Mocetti, Eliana Viviano, Massimo Gallo, Andrea Petrella, Paolo Sestito, Ludovica Giua, Roberto Nisticò, Claudio Deiana, Paolo Naticchioni, Dario Sciulli, the Editor, two anonymous referees and seminar participants at Veneto Lavoro, University of Milan, the Bank of Italy, and at EALE, ERSA, AIEL, SIE and Brucchi Luchino conferences/workshops for useful comments and critiques. Suzanne Dingee provided great editorial assistance. All remaining errors are ours. The views expressed in this paper are those of the authors and do not necessarily reflect those of the Bank of Italy.

Responsible editor: Sara de la Rica

\section{Author details}

${ }^{1}$ Bank of Italy, Regional Economic Research Division - Florence Branch, via dell'Oriuolo 37/39, 50122 Florence, Italy. ${ }^{2}$ Centre for the Analysis of Public Policies, University of Modena and Reggio Emilia, viale Berengario 51, 41121 Modena, Italy. ${ }^{3}$ Bank of Italy, Structural Economic Analysis Directorate, via Nazionale 91, 00184 Rome, Italy.

Received: 20 August 2014 Accepted: 16 January 2015

Published online: 19 March 2015

\section{References}

Anastasia B, Disarò M, Gambuzza M, Rasera M (2009) Comunicazioni obbligatorie e analisi congiunturale del mercato del lavoro: evoluzione, problemi metodologici, risultati. Veneto Lavoro, Collana "I tartufi" n. 35

Anastasia B, Disarò M, Emireni G, Gambuzza M, Rasera M (2010) Guida all'uso delle Comunicazioni Obbligatorie nel monitoraggio del mercato del lavoro. Seconda versione: dicembre 2010. Veneto Lavoro, Collana "I tartufi" n. 36

Anastasia B, Giraldo A, Paggiaro A (2013) L'effetto degli incentivi alle assunzioni e alle trasformazioni. Prime evidenze per il Veneto. Politica Economica 181-198. doi: 10.1429/76222

Angrist JD, Pischke JS (2009) Mostly Harmless Econometrics. Princeton University Press, Princeton

Barbieri G, Sestito P (2008) Temporary Workers in Italy: Who Are They and Where They End Up? Labour 22(1):127-166

Battiloro V, Mo Costabella L (2011) Incentivi o misure di attivazione? Evidenze sull'efficacia di due interventi per contrastare il lavoro precario. Politica Economica 197-218. doi: 10.1429/35198

Bertola G (1990) Job security, employment and wages. Eur Econ Rev 34(4):851-879

Berton F, Devicienti F, Pacelli L (2011) Are temporary jobs a port of entry into permanent employment? Evidence from matched employer-employee data. Int J Manpo 32(8):879-899

Blundell R, MaCurdy T (1999) Labor supply: A review of alternative approaches. In: Ashenfelter O, Card D (eds) Handbook of Labor Economics, edition 1, vol 3. Elsevier, North-holland, pp 1559-1695

Blundell R, Francesconi M, van der Klaauw W (2011) Anatomy of Welfare Reforms: Announcement and Implementation Effects. IZA Discussion Papers No. 6050, Institute for the Study of Labor

Boeri T, Jimeno J (2005) The effects of employment protection: learning from variable enforcement. Eur Econ Rev 49(8):2057-2077

Booth AL, Francesconi M, Frank J (2002) Temporary Jobs: Stepping Stones or Dead Ends? Econ J 112:F189-F213

Bruno GSF, Caroleo FE, Dessy O (2012) Stepping Stones versus Dead End Jobs: Exits from Temporary Contracts in Italy after the 2003 Reform. IZA Discussion Paper No. 6746, Institute for the Study of Labor

Cipollone P, Guelfi A (2003) Tax credit policy and firms' behaviour: the case of subsidies to open-end contracts in Italy. Temi di Discussione No. 471, Bank of Italy

Cipollone P, Guelfi A (2006) Financial support to permanent jobs. The Italian case. Politica Economica 51-76. doi: $10.1429 / 21830$

Grassi E (2009) The effect of EPL on the conversion rate of temporary contracts into permanent contracts: Evidence from Italy. Giorn Econ Ann Econ 68(2):211-231

Hernanz V, Jimeno JF, Kugler AD (2003) Employment consequences of restrictive permanent contracts: Evidence from Spanish labour market reforms. CEPR Discussion Papers 3724

Ichino A, Mealli F, Nannicini T (2005) Temporary Work Agencies in Italy: A Springboard Toward Permanent Employment? Giorn Econ Ann Econ 64(1):1-27

Karaca-Mandic P, Norton EC, Dowd B (2012) Interaction Terms in Non-linear Models. Health Serv Res 47:255-274 
Kugler A, Pica G (2008) Effects of employment protection on worker and job flows: Evidence from the 1990 Italian reform. Labour Econ 15(1):78-95

Maurin E, Michaud M (2004) The Effects of Increasing the Costs of Fixed-Term Contracts on the Dynamics of Labor Demand: An Evaluation of a French Reform. Paper presented at the CEPR/ECB Labour Market Conference, available at http://dev3.cepr.org/meets/wkcn/4/4539/papers/maurin.pdf

Maurizio D (2006) Giove: un database statistico sul mercato del lavoro Veneto. Veneto Lavoro, Collana "I tartufi" n. 22

Méndez I (2013) Promoting Permanent Employment: Lessons from Spain. Series 4(2):175-199

Ministero del Lavoro e delle Politiche Sociali (2013) Incentivi per il lavoro in favore di donne e giovani under 29.

http://www.lavoro.gov.it/Notizie/Pages/20130610_Incentivi_giovani_donne.aspx. Accessed 20 Jan 2014

Picchio M (2008) Temporary Contracts and Transitions to Stable Jobs in Italy. Labour 22(s1):147-174

Puhani PA (2012) The treatment effect, the cross difference, and the interaction term in nonlinear "difference-in-differences" models. Econ Lett 115:85-87

Schivardi F, Torrini R (2008) Identifying the effects of firing restrictions through size-contingent differences in regulation. Labour Econ 15(3):482-511

Submit your manuscript to a SpringerOpen ${ }^{\circ}$ journal and benefit from:

- Convenient online submission

- Rigorous peer review

- Immediate publication on acceptance

- Open access: articles freely available online

- High visibility within the field

- Retaining the copyright to your article

Submit your next manuscript at $\gg$ springeropen.com 